\title{
A multi-method approach to studying the relationship between character strengths and vocational interests in adolescents
}

\author{
René T. Proyer • Nicole Sidler • Marco Weber • \\ Willibald Ruch
}

Received: 13 June 2011/Accepted: 16 February 2012/Published online: 21 April 2012

(C) Springer Science+Business Media B.V. 2012

\begin{abstract}
The relationship between character strengths and vocational interests was tested. In an online study, 197 thirteen to eighteen year-olds completed a questionnaire measuring character strengths and a multi-method measure for interests (questionnaire, nonverbal test, and objective personality tests). The main findings were that intellectual strengths yielded primarily relations with investigative and artistic interests. Social interests demonstrated relations with strengths of transcendence and other-directed strengths and enterprising interests with leadership strengths. The implications of the findings for practice are highlighted.
\end{abstract}

Résumé. Une approche multi-méthode de l'étude de la relation entre les forces de caractère d'adolescents et les intérêts professionnels. La relation entre les forces de caractère et les intérêts professionnels a été testée. Dans une étude en ligne, 197 sujets âgés de treize à dix-huit ans ont complété un questionnaire mesurant les forces de caractère et une mesure multi-méthode des intérêts (questionnaire, test non-verbal, et tests de personnalité objectif). Les résultats principaux montrent que les forces intellectuelles sont surtout reliées avec des intérêts de type investigateur et artistique. Les intérêts de type social sont liés avec les forces de transcendance et d'autres forces et intérêts entrepreneurial dirigé vers les forces de leadership. Les implications pour la pratique sont mises en évidence.

Zusammenfassung. Ein multimethodischer Ansatz zur Erforschung des Zusammenhangs zwischen Charakterstärken und beruflichen Interessen bei Jugendlichen. Es wurde der Zusammengang zwischen Charakterstärken und

R. T. Proyer $(\bowtie) \cdot$ N. Sidler $\cdot$ M. Weber $\cdot$ W. Ruch

Department of Psychology, University of Zurich, Binzmühlestrasse 14/7, 8050 Zurich, Switzerland e-mail: r.proyer@psychologie.uzh.ch

Present Address:

N. Sidler

Bureau of Career Counseling of the Canton, St. Gallen, Switzerland 
Berufsinteressen untersucht. In einer Onlinestudie haben 197 Jugendliche zwischen 13 und 17 Jahren einen Fragebogen zu Charakterstärken und eine multimethodische Testbatterie zur Erfassung von Interessen (ein Fragebogen, ein nonverbaler Test und sog. Objektive Persönlichkeitstests) bearbeitet. Hauptergebnisse waren, dass hauptsächlich intellektuelle Stärken mit intellektuell-forschenden und künstlerischsprachlichen Interessen zusammenhingen. Für soziale Interessen fanden sich Zusammenhänge mit Stärken der Transzendenz und solchen Stärken, die auf andere ausgerichtet sind. Unternehmerische Interessen gingen mit Stärken einher, die sich auf Führungsvermögen beziehen. Im Weiteren werden Implikationen der Ergebnisse für die Praxis vorgestellt.

\section{Resumen. Un acercamiento multi-métodico al estudio de la relación entre las fortalezas de carácter de los adolescentes y los intereses vocacionales. La rela- ción entre fortalezas de carácter e intereses vocacionales fue probada. En un estudio en Internet, 197 participantes entre los 13 y los 18 años completaron un cuestionario que mide las fortalezas de carácter al igual que un multi-método que determina los intereses (cuestionario, test no verbal y tests de objetivos de personalidad). Los resultados principales indican que las fortalezas intelectuales se relacionan princi- palmente con intereses investigativos y artísticos. Intereses sociales demostraron un vínculo con fortalezas de transcendencia y otras fortalezas mas directas. Por otro lado, los intereses de empresa corresponden a fortalezas de liderazgo. Las impli- caciones de estos resultados en la practica son resaltados.}

Keywords Character strengths - Vocational interests - Objective personality test

Positive psychology is the scientific study of what is best in people (Seligman and Csikszentmihalyi, 2000). Its emphasis is on positive psychological functioning and positive characteristics, such as character strengths, virtues, or talents. There is lot of research on the correlates of vocational interests, but comparatively little research on their relationship with morally positively valued personality traits. Peterson and Seligman (2004) saw character strengths as such traits and argued that they enable a "good life," as they are psychologically fulfilling. They developed the Values in Action (VIA) classification of strengths and virtues for structuring the field. Three to five strengths are assigned theoretically to one of six universal virtues (i.e., wisdom and knowledge, justice, courage, humanity, temperance, and transcendence). The strengths are the processes and mechanisms that enable the practice of a virtue (e.g., pursuing love of learning, curiosity, or creativity for practicing wisdom).

Peterson, Park, and Seligman (2005) developed the Values in Action-Inventory of Strengths (VIA-IS) for the subjective assessment of individual differences in the 24 VIA-strengths in adults. Park and Peterson (2006) authored an analogous instrument for adolescents: Values in Action Inventory of Strengths for Youth (VIA-Youth). In line with theoretical expectations, character strengths were found to be predictive for positive life outcomes, such as life satisfaction (e.g., Park \& Peterson, 2006; Ruch, Weber, Park, \& Peterson, in press). Findings from 
educational settings are also encouraging. For example, sixteen of the VIA-strengths were positively associated (between $r=.14$ and $.31, N=205$ ) with academic success (grade point average, GPA) in college (Lounsbury, Fisher, Levy, \& Welsh, 2009). Specific character strengths were associated with end-of-year GPA (while controlling for achievement scores and demographics) and with social skills (i.e., cooperation, assertion, empathy, or self-control) in 5th and 8th graders (Park \& Peterson, 2006). Some character strengths were identified as relevant for positive behavior in the classroom, which, in turn, was found to be predictive for school success in school children (Weber \& Ruch, in press). These skills could be relevant for making career decisions (e.g., when gathering information from others or thinking about educational opportunities). Overall, these researchers suggested that strengths play an important role in this challenging period of time of transition during school and then from school to working life.

The VIA measures were developed for assessing multiple facets of good character and for differentiating among single strengths. Several studies proposed a five-factor solution for the underlying structure of the VIA-Youth (Gillham et al., 2011; Ruch et al., in press). This converges with the theoretical assumptions (Peterson \& Seligman, 2004) but does not fully overlap with it. The factors commonly found for the VIAYouth are (1) intellectual strengths (i.e., curiosity, love of learning, appreciation of beauty and excellence, and creativity); (2) leadership strengths (i.e., leadership, humor, perspective, social intelligence, and bravery); (3) other-directed strengths (i.e., modesty, forgiveness, kindness, fairness, and teamwork); (4) temperance strengths (i.e., prudence, self-regulation, perseverance, open-mindedness, and honesty); and (5) transcendence strengths (i.e., religiousness, zest, gratitude, love, and hope). The analyses in this study were conducted primarily at the level of these strengths factors.

This is the first study to empirically examine the relationships between character strengths and vocational interests. A better understanding of these relationships may have several practical implications. For example, it may be useful to understand these relationships when working with clients on their strengths or for facilitating career decision-making processes. Also, it may be beneficial to clients to consider the fit between single strengths or broader strength factors derived from a well-established classification scheme and preferences for vocations in the counseling process (e.g., other-directed strengths and interest in working with people or helping people). However, the job-strengths fit also seems to be relevant for placement decisions and consequences. For example, character strengths have been linked to positive workbehavior (i.e., health promoting work and experience patterns; Gander, Proyer, Ruch, \& Wyss, in press), and a focus on employees' strengths has been shown to facilitate work engagement (cf. Harter \& Blacksmith, 2010). Pursuing one's interests and one's core strengths (i.e., signature strengths) is expected to elicit positive emotions, which, in turn, can facilitate subjective well-being (Fredrickson, 2001). This study was aimed at providing initial empirical data on the relationship between strengths and interests and for discussing the potential exploitation of this relationship between strengths and vocational interests in counseling.

For testing these relationships, Holland's (1997) well-established trait-and-factor theory was used as a framework. It is important to note that, according to Holland, choosing a vocation is an expression of personality and, therefore, that interest 
inventories are personality inventories. He structured vocational interests in a framework into six broad categories (i.e., realistic, investigative, artistic, social, enterprising, and conventional; RIASEC). RIASEC types are associated with preferences for vocational activities (e.g., the manipulation of machines in the realistic type) but also with aversions (e.g., for therapeutic activities in the realistic type).

Expectations on the relationship between strengths and interests were derived from Holland's (1997) descriptions of traits that are related to the RIASEC types. These can be "translated" into the strengths vocabulary and hypotheses for single strengths and broader strengths factors can be set up. For example, Holland notes that the realistic type "avoid[s] activities demanded by social occupations or situations" and "values concrete things or tangible personal characteristics. Possesses a very closed system of beliefs and values (i.e., not open to change in beliefs and behavior)" (p. 21). Based on these descriptions, we hypothesized that greater realistic interests would point towards lower perspective but higher levels of persistence. The deficit of "persuasive competencies" of the investigative type was expected to be associated with lower expressions in the leadership strengths (e.g., trait-descriptors like critical, which translates into the strength of perspective) but greater expressions in intellectual strengths such as, love of learning, curiosity; other expectations were derived from descriptors such as cautious (translates into the strength of prudence) and pessimistic (low hope). The artistic type "value[s]... aesthetic experience and achievement" (p. 24) and trait descriptors are, for example, imaginative/original (curiosity, creativity), or open (open-mindedness). The social type is characterized by interpersonal competencies, such as "seeking mutual interactions and help from others" (p. 25). Trait-descriptors are, for example, cooperative (teamwork), or forgiving/friendly (kindness). The enterprising type can be described by adjectives such as ambitious (zest, love of learning), or energetic/enthusiastic (zest). Finally, the conventional type "believes that aesthetic activities and close companionship as well as being forgiving and imaginative are of lesser value" (p. 27). Trait-descriptors are inflexible (low open-mindedness, creativity), or persistent (persistence).

Based on these descriptions and the overview of the literature, it was expected that vocational interests primarily would relate to intellectual strengths, especially, the investigative and artistic themes. Within these themes, curiosity and creativity can be seen as core components of the respective occupations. Social interests primarily were expected to relate to other-directed strengths but also to temperance strengths. Leadership strengths (but also intellectual strengths) should, of course, relate to greater enterprising interests. Since realistic interests have a strong focus on manual skills, and since they were together with the conventional interests least well represented in the theoretical considerations, the comparatively lowest relationships with strengths were expected for these two themes.

We used a multi-method approach to assess vocational interests in this study. The Multi-method Objective Interest Test-battery (MOI; Proyer \& Häusler, 2008) assesses vocational interests by means of (a) a questionnaire, (b) a nonverbal test, and (c) experimental tests (objective personality tests in the sense of Cattell \& Warburton, 1967; cf. Proyer \& Häusler 2007a). The latter are based on the idea that vocational interests manifest themselves in specific behavior that can be observed in standardized settings. For example, people's attention when reading texts may vary 
depending on their interest in the text; people spend money differently depending on their interest; or the interpretation of ambiguous material can be adjusted to their interests. The rationale behind these tests builds upon earlier approaches (e.g., Cattell, 1950, 1968; Fryer, 1931; Super \& Roper, 1941) and is described in further detail elsewhere (Proyer, 2007; Proyer \& Häusler, 2008). In this study, the comparison of the findings for the questionnaire and the nonverbal test allows for testing which relationships are most stable and which can only be found in one of the two (method bias). Objective tests usually correlate low with self-report instruments, but it is argued that they provide further information that potentially cannot be assessed by self-reports only (Proyer, 2007; Proyer \& Häusler, 2007b). Their more experimentally driven nature can reveal hypotheses useful in conducting future studies. Such a multi-method approach allows a close evaluation of the relationships between strengths and interests. Based on the findings, implications for the practice will be derived and discussed.

The main aim of the present study was testing the relationship between character strengths and vocational interests. A computerized, multi-methodic test battery for the assessment of vocational interests was used. We tested whether specific relations were stable across different conditions-i.e., in self-reports, but also in more behavior-based measures. The strengths were mainly inspected at the level of broader strengths factors, but also at the level of single strengths.

\section{Method}

Participants

The sample consisted of 197 adolescents. They were between 13 and 18 years of age $(M=16.2, \mathrm{SD}=1.7)$. About a fifth were males $(n=39,19.8 \%)$. About three quarters attended a type of school qualifying them for the attendance of a university with their school-leaving diploma $(n=143,72.6 \%)$.

Instruments

Multi-method Objective Interest Test-battery (MOI; Proyer \& Häusler, 2008)

The MOI is a computerized test battery for assessing vocational interests based on Holland's (1997) typology by (a) a questionnaire that consists of 96 items depicting vocational activities (e.g., "repairing" or "filing"), for which participants need to decide on whether they have or do not have an interest in this activity); (b) a nonverbal test that consists of 60 hand-drawn figures that are gender neutral, showing either people in a vocational situation (e.g., in a bakery or a flower shop) or tools used for carrying out specific jobs (e.g., a screw driver or a music stand); and (c) three objective tests (see Proyer, 2007; Proyer \& Häusler, 2007a) that are summed up into a total score (i.e., distributing money to different organizations, finding target words in a text, and interpreting ambiguous pictures). The completion of the full battery takes about 35-40 min. Data reported by Proyer and Häusler 
(2008) supported the reliability (internal consistency) and validity (convergent and divergent) of the MOI. The MOI, as well as single tests out of the battery, already have been used in previous studies (Proyer, 2006; Proyer \& Häusler, 2007b). In this sample, the $\alpha$-coefficients were between .86 and .92 (questionnaire) and between .73 and .90 (nonverbal test). The test principle does not allow for the computation of reliabilities for all of the objective tests (see Proyer \& Häusler, 2008), but split-half reliabilities for the ambiguous pictures-test were between .53 and $.69(M=.61)$.

\section{Values in Action Inventory of Strengths for Youth (VIA-Youth; Park \& Peterson,} 2006; German version by Ruch et al., in press)

The VIA-Youth consists of 198 items for assessing the 24 character strengths of the VIA-classification (Peterson \& Seligman, 2004). There are 7-9 items per character strength, and about one-third of them are reverse coded. Answers are given on a five-point Likert-type scale ( 1 = not like me at all, $5=$ very much like me), and a sample item is, "When I see people who need help, I do as much as I can" (kindness). It has already been used in several studies that support its reliability and validity (e.g., Park \& Peterson, 2006; Ruch et al., in press). $\alpha$-coefficients for the single scales in this sample ranged between .68 and .91 (median $=.80$ ). Scales for the five broader factors were computed as described in Gillham et al. (2011): Their internal consistencies were .92 (transcendence), .91 (temperance), .91 (intellectual), .89 (other-directed), and .92 (leadership).

\section{Procedure}

The study was advertised in career counseling centers in the greater Zurich (Switzerland) area. Additionally, information on the study was sent out to school administrations and teachers. Leaflets were distributed near schools and large public transport stations. All data were collected online. Participants completed the measures voluntarily and individually at home or at school. Before completion of the scales, the participants had to ask for parental permission as a precondition for participation. Contact information (e-mail) was given in case of any questions. Participants completed demographics and the VIA-Youth first; afterwards they received a personalized invitation by e-mail for the completion of the MOI (also online). A personalized written feedback on his/her profile of interests and character strengths was sent to each participant via e-mail. Advice to contact local counselors was given in case of further questions regarding career decisions. Full testing time was about 60-90 min, depending on the age and working speed of the participants.

\section{Results}

Preliminary analyses

Mean scores and standard deviations were computed for all scales that entered the study. Additionally, correlations with age were computed and mean 
scores for girls and boys were compared (independent samples $t$ tests; see Table 1).

The mean scores and standard deviations shown in Table 1 were compared with studies that have been conducted with the German VIA-Youth and the MOI, and they were comparable to what has been reported in the literature (Proyer \& Häusler, 2008; Ruch et al., in press). Age did not contribute to the expression of the scales (the median of all correlation coefficients was -.01 and the largest [persistence] had an $\left.r^{2}=.04\right)$. Girls exceeded the mean scores of boys in other-directed strengths. Regarding Holland types on the MOI, boys scored higher in realistic interests than girls, while girls were higher in artistic and social interests. Boys also scored higher in realistic interests in the nonverbal test. Additionally, they were higher in enterprising interests in the nonverbal test and in the objective tests. We subsequently conducted analyses and controlled for potential effects of age and gender.

Analyses at the five strengths factors level

For a first evaluation of the relationships between strengths and interests, we computed canonical correlations between the six vocational themes (separately for the questionnaire, the nonverbal test, and the objective tests) and the five broader strengths factors. Therefore, we could estimate the explanatory power of one instrument over the other at higher-level dimensions. For the questionnaire in the MOI and the VIA-Youth, four canonical dimensions were significant. The canonical correlation of the first dimension was $.57, F(30,1062)=6.80, p<.001$, and was mainly associated with investigative and artistic interests and intellectual strengths); .36 for the second, $F(20,883.17)=4.24, p<.001$, and was associated with enterprising interests and leadership strengths; .32 for the third, $F(12,706.71)$ $=3.82, p<.001$, and was associated with social interests, other-directed strengths, and transcendence); and .23 for the fourth, $F(6,536)=2.65, p<.001$, and was mainly negatively associated with temperance strengths.

Analyses were repeated with the same specifications for the nonverbal test and three canonical dimensions were significant. The first dimension yielded a canonical correlation of $.48, F(30,1082)=4.34, p<.001$, and was mainly associated with artistic interests and intellectual strengths; the second of .32, $F(20,899.76)=2.67$, $p<.001$ and was mainly investigative interests and temperance; and the third of $.20, F(12,719.94)=1.97, p<.05$, and was mainly negatively associated with social interests, temperance, other-directed, and leadership strengths.

Finally, analyses were repeated for the objective personality tests in the MOI. In this analysis, one canonical correlation was significant, and the coefficient was .42, $F(30,1018)=2.20, p<.001$, and was mainly associated with artistic interests and intellectual strengths.

For a more detailed evaluation and further illustration of the relationships, partial correlations (controlling for age and gender) were computed between the VIAYouth scales and the MOI-scores, and separately for the questionnaire, the nonverbal test, and the objective tests. Table 2 shows that there were between 5 and $29 \%$ overlapping variance between vocational interests and character strengths 
Table 1 Demographics, correlations with age, and mean level comparisons between boys and girls for measures of character strengths and vocational interests

\begin{tabular}{|c|c|c|c|c|c|c|c|c|}
\hline \multirow[b]{2}{*}{ Scale } & \multicolumn{3}{|l|}{ Total } & \multicolumn{2}{|l|}{ Girls } & \multicolumn{2}{|l|}{ Boys } & \multirow{2}{*}{$\begin{array}{l}\text { Difference } \\
d\end{array}$} \\
\hline & $M$ & SD & Age & $M$ & SD & $M$ & SD & \\
\hline \multicolumn{9}{|l|}{$V I A-Y$} \\
\hline TRA & 3.67 & 0.51 & -.10 & 3.68 & 0.49 & 3.64 & 0.56 & - \\
\hline TEM & 3.62 & 0.40 & -.07 & 3.60 & 0.38 & 3.66 & 0.46 & - \\
\hline INT & 3.73 & 0.49 & .09 & 3.74 & 0.49 & 3.70 & 0.48 & - \\
\hline OTH & 3.90 & 0.33 & .08 & $3.95^{\mathrm{a}}$ & 0.32 & $3.74^{\mathrm{a}}$ & 0.32 & 0.66 \\
\hline LEA & 3.71 & 0.41 & -.05 & 3.71 & 0.42 & 3.70 & 0.41 & - \\
\hline \multicolumn{9}{|c|}{$M O I-Q$} \\
\hline $\mathrm{R}$ & 3.74 & 4.69 & -.10 & $2.99^{\mathrm{a}}$ & 4.01 & $6.77^{\mathrm{a}}$ & 5.97 & 0.74 \\
\hline I & 8.88 & 4.48 & .04 & 8.80 & 4.09 & 9.18 & 5.87 & - \\
\hline A & 9.30 & 4.54 & .06 & $9.68^{\mathrm{a}}$ & 4.17 & $7.77^{\mathrm{a}}$ & 5.59 & 0.39 \\
\hline$S$ & 10.58 & 4.31 & .13 & $10.94^{\mathrm{a}}$ & 4.01 & $9.10^{\mathrm{a}}$ & 5.19 & 0.40 \\
\hline $\mathrm{E}$ & 7.62 & 4.42 & .01 & 7.43 & 4.17 & 8.41 & 5.32 & - \\
\hline $\mathrm{C}$ & 6.76 & 4.57 & -.06 & 6.54 & 4.29 & 7.62 & 5.55 & - \\
\hline \multicolumn{9}{|c|}{$M O I-N$} \\
\hline $\mathrm{R}$ & 2.23 & 3.11 & -.07 & $1.70^{\mathrm{a}}$ & 2.63 & $4.36^{\mathrm{a}}$ & 3.96 & 0.79 \\
\hline I & 4.51 & 2.86 & .01 & 4.37 & 2.65 & 5.10 & 3.58 & - \\
\hline A & 5.28 & 3.16 & .02 & 5.46 & 2.97 & 4.54 & 3.78 & - \\
\hline S & 4.86 & 3.02 & .09 & 5.02 & 2.86 & 4.23 & 3.59 & - \\
\hline $\mathrm{E}$ & 4.27 & 2.81 & -.05 & $4.03^{\mathrm{a}}$ & 2.61 & $5.26^{\mathrm{a}}$ & 3.35 & 0.41 \\
\hline $\mathrm{C}$ & 3.89 & 2.77 & -.06 & 3.77 & 2.58 & 4.41 & 3.40 & - \\
\hline \multicolumn{9}{|c|}{ MOI-O } \\
\hline $\mathrm{R}$ & 100.14 & 10.76 & -.08 & 99.70 & 10.49 & 101.90 & 11.77 & - \\
\hline I & 101.14 & 10.37 & $.16^{*}$ & 101.75 & 10.62 & 98.67 & 8.97 & - \\
\hline A & 99.33 & 11.17 & .08 & 99.58 & 11.15 & 98.33 & 11.34 & - \\
\hline S & 100.85 & 11.99 & .03 & 101.61 & 11.71 & 97.77 & 12.78 & - \\
\hline $\mathrm{E}$ & 97.50 & 9.36 & -.10 & $96.74^{\mathrm{a}}$ & 8.70 & $100.56^{\mathrm{a}}$ & 11.28 & 0.41 \\
\hline $\mathrm{C}$ & 98.51 & 9.12 & -.07 & 97.82 & 8.33 & 101.31 & 11.51 & - \\
\hline
\end{tabular}

$N=197(n=158$ girls, $n=39$ boys $)$

$M$ mean, $S D$ standard deviation, $d$ Cohen's d, VIA- $Y$ Values in Action Inventory of Strengths for Youth, $T R A$ transcendence, TEM temperance, INT intellectual, $O T H$ other-directed, $L E A$ leadership, $R$ realistic, $I$ investigative, $A$ artistic, $S$ social, $E$ enterprising, $C$ conventional, $M O I$ Multi-method Objective Interest Test-battery ( $Q$ questionnaire, $N$ nonverbal test, $O$ objective tests)

${ }^{a}$ Means sharing a superscript differ significantly $(p<.05)$

$* p<.05 ; * * p<.01$

(questionnaire data) with intellectual strengths demonstrating the greatest numerical convergence. The largest determination coefficients were found for investigative and artistic interests, enterprising, and, to a lesser degree, conventional interests also increased with greater intellectual strengths. As expected, other-directed strengths 
Table 2 Partial correlations (controlled for age and gender) between character strengths and vocational interests as measured by a questionnaire, nonverbal test, and objective test

\begin{tabular}{|c|c|c|c|c|c|}
\hline Interests & Transcendence & Temperance & Intellectual & Other & Leadership \\
\hline \multicolumn{6}{|l|}{ Questionnaire } \\
\hline Realistic & -.02 & .00 & .12 & .10 & -.01 \\
\hline Investigative & .10 & $.19 * *$ & $.41 * * *$ & $.20 * *$ & .11 \\
\hline Artistic & $.16^{*}$ & .07 & $.45 * * *$ & $.18^{*}$ & $.17 *$ \\
\hline Social & $.23 * *$ & .10 & .14 & $.22 * *$ & $.19 * *$ \\
\hline Enterprising & .08 & .09 & $.24 * *$ & .14 & $.26 * * *$ \\
\hline Conventional & -.02 & .10 & $.15^{*}$ & .10 & .09 \\
\hline$R^{2}$ & .07 & .05 & .29 & .09 & .09 \\
\hline \multicolumn{6}{|l|}{ Nonverbal } \\
\hline Realistic & -.05 & .01 & .04 & .08 & -.06 \\
\hline Investigative & .01 & $.16^{*}$ & $.31 * * *$ & .12 & .03 \\
\hline Artistic & .14 & .01 & $.35 * * *$ & $.18^{*}$ & .06 \\
\hline Social & .09 & .11 & .05 & $.18^{*}$ & .03 \\
\hline Enterprising & .04 & .10 & $.16^{*}$ & .13 & .13 \\
\hline Conventional & -.08 & .11 & .07 & .06 & .04 \\
\hline$R^{2}$ & .06 & .04 & .21 & .09 & .09 \\
\hline \multicolumn{6}{|l|}{ Objective } \\
\hline Realistic & .01 & .06 & -.11 & .08 & .01 \\
\hline Investigative & .01 & .00 & .09 & -.04 & -.06 \\
\hline Artistic & .04 & -.08 & $.24 * *$ & .02 & -.05 \\
\hline Social & .06 & $.15^{*}$ & -.13 & .00 & .12 \\
\hline Enterprising & -.06 & .00 & .04 & .02 & .10 \\
\hline Conventional & -.04 & .01 & .02 & .09 & .01 \\
\hline$R^{2}$ & .01 & .04 & .10 & .02 & .03 \\
\hline
\end{tabular}

$N=197$

Other other-directed strengths; $R^{2}$ multiple correlation coefficient

$* p<.05 ; * * p<.01 ; * * * p<.001$

were associated with greater social, but also investigative and artistic interests. Likewise, the positive relationship between leadership strengths and enterprising interests was expected. Social and artistic interests were associated with leadership strengths, with transcendence strengths showing greater association with social and artistic interests. Finally, temperance strengths correlated with investigative interests.

Findings were similar for the nonverbal interests, except that transcendence and leadership strengths did not demonstrate any significant correlation coefficients. There was a strong relationship between investigative and artistic interests and intellectual strengths. As expected, vocational interests measured via objective tests yielded the lowest numerical correlations. They demonstrated between 1 and $10 \%$ overlapping variance with the five strengths factors. Pertaining to the questionnaire data and the nonverbal test, the highest numerical relationships were found for 
intellectual strengths. Again, artistic interests were positively related to intellectual strengths.

Analyses at the single-strengths level

We computed correlations at the 24-character-strengths level. A few of the most important findings should be highlighted. For example, in the questionnaires (VIAYouth and MOI), the highest numerical relationships were found between love of learning $(r=.40)$ and curiosity $(r=.39)$ and investigative interests. Appreciation of beauty and excellence $(r=.48)$ and creativity $(r=.39)$ as well as curiosity $(r=.28)$ demonstrated strong relationships with artistic interests. Creativity $(r=.30)$, self-regulation $(r=.26)$, and hope $(r=.24)$ yielded relationships with investigative interests. Greater leadership $(r=.28)$ and creativity $(r=.24$; all $p<.01)$ correlated with enterprising interests. Love of learning $(r=.20)$, curiosity $(r=.17)$, and leadership $(r=.16)$ were the only strengths that were related to conventional interests. Realistic interests tended to increase with forgiveness $(r=.17)$ and modesty $(r=.16$, all $p<.05)$.

Findings for the nonverbal test were similar to what has been reported for the questionnaire data. Most importantly, we found a negative relationship between realistic interests and perspective $(r=-.15)$, and greater self-regulation was associated with social $(r=.19)$, enterprising $(r=.16)$, and conventional interests $(r=.16$, all $p<.05)$. Again, the more experimentally oriented objective tests yielded the lowest numerical relationships with the self-reported character strengths. The objectively tested social interests correlated with greater persistence $(r=.17)$ and lower appreciation of beauty and excellence $(r=-.23)$; modesty with lower investigative $(r=-.17)$ and prudence with lower artistic interests $(r=-.16$, all $p<.05)$. When interpreting these findings, only coefficients $\geq .25$ were significant if controlling for multiple comparisons (Bonferroni-correction; i.e., none of the coefficients for the nonverbal or objective tests).

When computing multiple correlation coefficients $\left(R^{2}\right)$ for each strength with the six Holland dimensions, the coefficients ranged from .02 (modesty) to .30 (appreciation of beauty and excellence; median $=.07$ ) for the questionnaire; between .01 (modesty) and .30 (appreciation of beauty and excellence; median $=.05$ ) for the nonverbal test; and between .01 (love, kindness, fairness, and hope) and .17 (appreciation of beauty and excellence; median $=.03$ ) for the objective tests.

Predicting vocational interests from character strengths

Six multiple hierarchical regression analyses were conducted with the RIASECdimensions as criteria (questionnaire data only). In each analysis, the criterion was predicted by (a) entering age and gender in a first step to the regression (method: enter) for controlling for potential effects of demographics and (b) entering the five strengths factors into the equation in a second step (method: stepwise). All analyses yielded significant predictions except for conventional interests, $R^{2}=.03, F(3$, 196) $=2.15, p=.10$. 
Table 3 shows that for realistic interests only male gender contributed to the prediction but none of the strengths. The best predictors for investigative and artistic interests were intellectual strengths, which demonstrated 16 and $19 \%$ overlapping variance, respectively. Social interests were different, as they were predicted by transcendence and other-directed strengths yet with lower predictive power (7\% shared variance). Finally, leadership strengths emerged as a potent predictor of enterprising interests (7 \% overlapping variance). When computing standard multiple regression analyses (not reported here in detail) instead of the stepwise regressions, similar findings were found. Notable differences were found for realistic interests, $R^{2}=.16, F(7,142)=3.73, p<.01$; male gender, $\beta=-.31$, $p<.001$; and also intellectual strengths, $\beta=.27, p<.01)$ yielded significant betaweights. For social interests, $R^{2}=.10, F(7,142)=2.24, p<.05$, only transcendence demonstrated a significant beta weight: $\beta=.23, p<.05$. For enterprising interests, $R^{2}=.17, F(7,142)=3.91, p<.01$, male gender, $\beta=-.22, p<.01$; leadership, $\beta=.24, p<.05$; and also intellectual strengths, $\beta=.20, p<.05$, yielded significant betas.

We hypothesized that the level of differentiation of the interest profiles played a role in the relationship of strengths and interests. The idea was that relationships varied depending on how clear the preferences regarding specific interests were among the participants. We used the bootstrapping approach recommended by Preacher and Hayes (2004) to test 5,000 bootstrap resamples. Estimates were computed for direct $\left(\mathrm{c}^{\prime}\right.$; strengths $\rightarrow$ vocational interests), indirect $(\mathrm{a} \times \mathrm{b}$; $\mathrm{a}=$ strengths $\rightarrow$ differentiation and $\mathrm{b}=$ differentiation $\rightarrow$ interests), and total effects $\left(\mathrm{c} ; \mathrm{c}=\mathrm{c}^{\prime}+\mathrm{a} \times \mathrm{b}\right)$. However, the analyses revealed only nonsignificant effects; even if some of them approached significance, it was concluded that the level of differentiation did not play a mediating role in the relationship of strengths and interests.

\section{Discussion}

This study provided the first empirical data on the relationship between the character strengths of the Values in Action-classification (Peterson \& Seligman, 2004) and Holland's (1997) vocational interest themes. Although, the focus on the interpretation of the findings lies in the results gathered from the same assessment method (questionnaires), canonical correlation analyses also supported the notion that the nonverbal and objective interest tests reflected specific relationships. Controlling for the effects of age and gender, we found relationships between components of "good character" and vocational interests, which fit the predictions well. Intellectual strengths (e.g., curiosity, love of learning) stood out, demonstrating the strongest numerical relationships (i.e., $29 \%$ overlapping variance with all six Holland themes, which is more than three times higher than any other strengthsinterest relationship). This might be due to the function of intellectual strengths in increasing adolescents' commitment to things that happen around them (cf. Gillham et al., 2011). It can be speculated that this contributes positively to the process of thinking about our own careers or vocations - and, later, to making career decisions. 


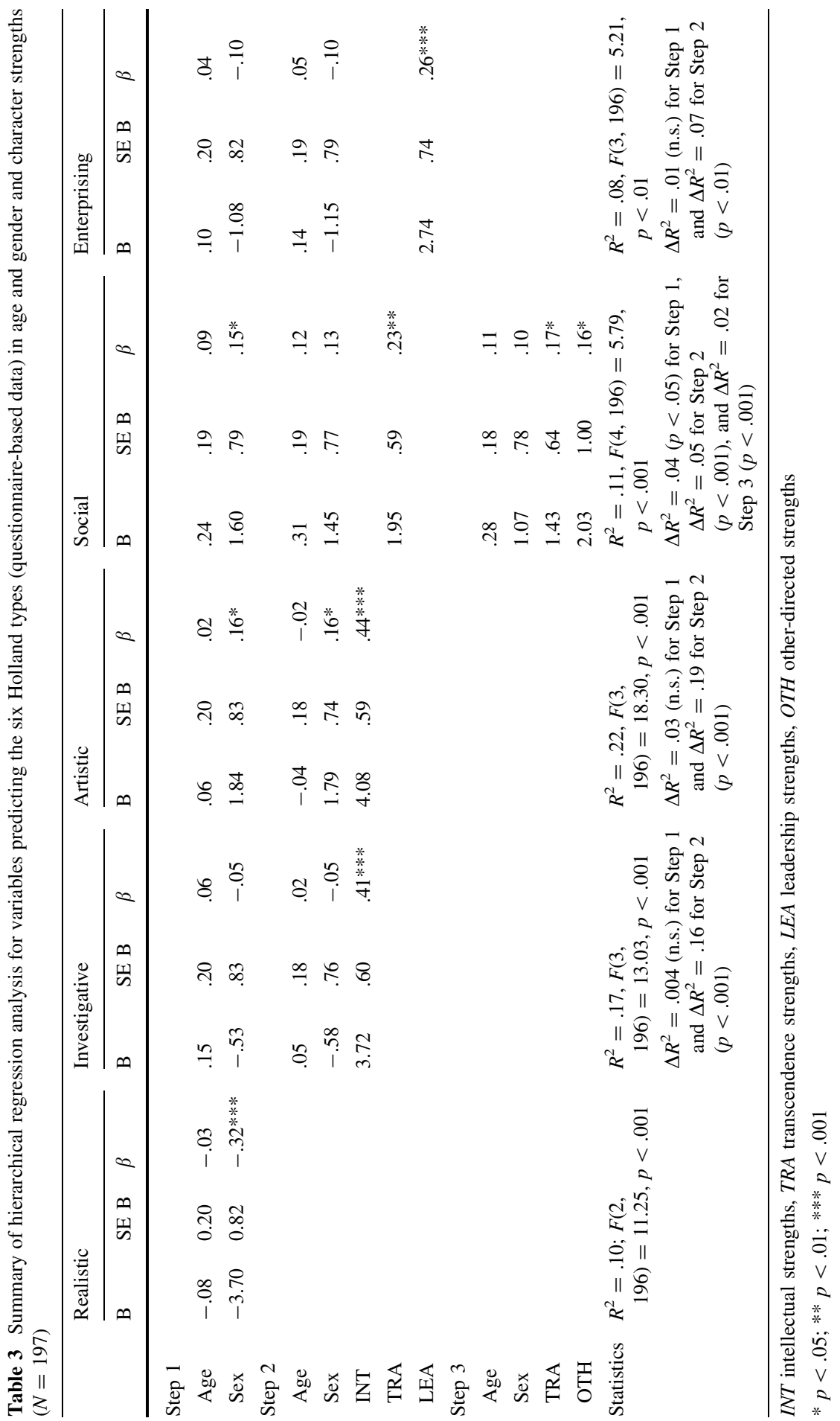


This relationship was also reflected at the level of single strengths, where we found strong relationships between investigative interests and strengths like creativity, curiosity, open-mindedness, and love of learning (three of which were assigned to intellectual strengths).

In regression analyses, investigative interests (17\% overlapping variance with the strengths factors) and artistic interests (22\%) were predicted by intellectual strengths; and social interests (11\%) were predicted by transcendence (e.g., hope, gratitude) and other-directed strengths (e.g., kindness, teamwork). While there was a low but significant correlation between conventional interests and intellectual strengths $\left(r^{2}=.02\right)$, neither the conventional nor the realistic themes were predicted by any of the strengths scales. Overall, there seems to be an overlap between virtuousness and the investigative, artistic, and social theme. It would be interesting to study further the role of "good character," career decisions, and work behavior. Earlier studies have indicated that specific strengths relate to health promoting work styles (e.g., Gander et al., in press), and it would be of interest to test how this relates to the interest-based person-environment fit. As in many other studies, male gender was associated with greater interest in realistic occupations (e.g., Proyer \& Häusler, 2007b; Bubany \& Hansen, 2011). However, interest in manual and office-related occupations seems widely unrelated to a person's strengths expression.

The findings do not indicate that persons in realistic and conventional professions or those aspiring to work in such professions do not have strengths. On the contrary, an important limitation to this sample is that about three-quarters of the participants attended schools whose diploma qualifies them to attend a university, and participants with vocational training were under-represented, when compared with the general population in Switzerland. This may also explain why in the standard multiple regression analysis, intellectual strengths contributed to the predication of realistic interests. Another limitation we acknowledge is that the results from the regression analysis were drawn from the particular sample in this study, which may or may not be generalizable to other samples. Thus, a replication of the findings in other countries or regions that are more diverse with regard to some specifications (e.g., socio-economic status) is needed. Analyses at the level of vocational activities instead of occupations, in general, seems to be of interest. Depending on the occupation and the activities that have to be conducted within realistic and conventional occupations, different strengths may play a role and could be considered in counseling situations (e.g., appreciation of beauty and excellence or creativity in some realistic activities; Proyer, 2007; Proyer \& Häusler, 2008).

The findings concerning the nonverbally assessed interests went in the same direction as and converged well with the intellectual strengths. As expected, there were only low numerical correlation coefficients between the VIA-Youth and the more experimentally oriented objective tests. Specific relationships, such as the one between artistic interests and intellectual strengths, also permeated into actual behavior that could be observed in these standardized settings; this also was reflected in a canonical correlation analysis where one variate that was mainly associated with particularly these interests and strengths was identified. These tests may also have potential for uncovering further relationships. For example, there was a hint towards greater persistence, but lower appreciation of beauty and excellence 
among those who endorsed social interests or lower modesty among investigative types. Thus, follow-up studies may address these aspects as they may represent yet uncovered areas of interests-those that cannot be covered by self-reports. The practical value of these tests is to create hypotheses for working with clients in daily practice, for example, when counseling clients who are unsure of what career to pursue in the future, or who are not sure about their vocational preferences. Using data that is independent from self-report can enrich this process by helping clients to think about new directions for their career decisions.

Although we found that the level of differentiation and, thus, how clear the preferences for specific interests were expressed did not mediate the relationship between strengths and interests, one might argue that results may differ when using an adult sample. In this phase the (first) orientation towards finding a job, building a career etc. has already been finished and, despite the stability of vocational preferences, may show different ways of experiencing strengths at work. Thus, it would be interesting to conduct a similar study with an adult sample. Finally, we acknowledge that the VIA-Youth was developed for use with children between the ages of 10-17 years old (Park \& Peterson, 2006). Since we have also 18 year-olds in our sample, we cannot rule out that their answer behavior or psychometric properties of the scale differs from younger participants.

\section{Implications for practice}

It has been argued that considering character strengths in career counseling is a valuable addition to the standard procedure. Expressing one's strengths in an occupation may be beneficial for experiencing greater satisfaction with one's job and may, eventually, lead to better performance at work.

For practical purposes, strengths-profiles of different vocational groups can be used as benchmarks in counseling sessions. Such profiles allow for a comparison of a client's profile with the standard profiles and provide information on the individual's fit with the respective environment. Additionally, such a strategy may be helpful for creating new interventions. Peterson and Seligman (2004) argued that strengths are malleable and, therefore, can be subjected to deliberate interventions. Such strengths-based interventions have been shown to positively impact life satisfaction and alleviate depression (Proyer, Ruch, \& Buschor, 2012; Seligman, Steen, Park, \& Peterson, 2005). Thus, counseling could focus on helping fostering strengths that are relevant for specific occupations.

In helping clients develop their potentials at work or enabling growth and flourishing, a deeper knowledge and understanding of one's strengths is crucial. It is expected that knowing and actively using one's strengths in daily life does not only have a positive impact on life satisfaction (Seligman et al., 2005) but can also facilitate positive experiences at work. For example, clients may learn to implement their signature strengths (i.e., their most characteristic strengths) into their daily routines. The climate in a meeting may be improved by a humorous comment, or expressing gratitude towards colleagues may enhance work relationships in a mutually effective manner. A fit of one's interests with the environment, as well as 
the opportunity of actively using one's strengths, can have beneficial effects on one's career development and work life in general.

An additional factor is that reporting strengths and potential resources, talents, or areas for development should be an incremental part of psychological reports (see Snyder, Ritschel, Rand, \& Berg, 2006). Thus, reporting results should not only help describing individual weaknesses and areas for improvement but also contain suggestions on how to cultivate strengths. We speculate that this may have an impact on the choice of vocations, the career-decision making process and, subsequently, career satisfaction. However, this study is of a cross-sectional nature only, and we cannot, therefore, comment on developmental processes. More research in this area, and on the impact strengths may have for career trajectories, is clearly indicated. A longitudinal study would be needed for deriving causal inferences. Different relationships may be possible. For example, one might argue that basic interests shape one's strengths, as they are the reason why people start engaging in certain activities and (through practicing) develop skills and strengths. One might also argue that having specific strengths leads to the endorsement of certain interests, for example, a curious, creative person with a high love of learning develops intellectual strengths as an expression of his/her interest.

Furthermore, it is argued that working with interests that are assessed in a multimethod approach can be beneficial for incorporating a broad perspective in the assessment of interests. Proyer (2007) described a model on how self-report measures and behavior-based measures (objective tests) could be used in practice. The main idea is that if the vocational identity and the differentiation of a profile are low, then the additional interpretation of the objective tests provides further information on the client's underlying interest structure. If the identity and the differentiation are high, the self-reports may seem better to represent what the person's interests are. Thus, this approach should allow for the description of a client's pattern of interests beyond self-report and should enable the development of hypotheses on interesting areas that may be followed in the counseling process.

One of the core tasks of future work in this area can be seen in educational settings. We argue that fostering positive psychological functioning in schools could have a positive impact on career decisions. Being aware of one's signature strengths, knowing how to use them, and living in accordance with them, could facilitate decisions towards a fulfilling career. However, much more work is needed in this area. This study is seen as an initial step towards integrating indicators of positive psychological functioning more strongly into practice.

Acknowledgments The completion of this paper was supported by the Swiss National Science Foundation with funding from the NCCR LIVES program (WR) and a program on research on positive interventions in different age groups (100014_132512/1; RTP and WR). The Schuhfried company supported this research by allowing the use of their test servers. The authors wish to thank Fabian Gander for his help with setting up the online survey and Katharina Klohe and Tracey Platt for proofreading the manuscript.

\section{References}

Bubany, S. T., \& Hansen, J.-I. C. (2011). Birth cohort change in the vocational interests of female and male college students. Journal of Vocational Behavior, 78, 59-67. doi:10.1016/j.jvb.2010.08.002. 
Cattell, R. B. (1950). The objective measurement of dynamic traits. Educational and Psychological Measurement, 10, 223-247. doi:10.1177/001316445001000204.

Cattell, R. B. (1968). The measurement of interest. In R. B. Cattell (Ed.), Personality and social psychology-Collected papers of Raymond B. Cattell (pp. 171-183). San Diego, CA: R. R. Knapp.

Cattell, R. B., \& Warburton, F. W. (1967). Objective personality and motivation test-A theoretical introduction and practical compendium. Urbana, IL: University of Illinois Press.

Fredrickson, B. L. (2001). The role of positive emotions in positive psychology: The broaden-and-build theory of positive emotions. American Psychologist, 56, 218-226. doi:10.1037//0003-066X.56.3. 218.

Fryer, D. (1931). The measurement of interests in relation to human adjustment. New York: Henry Holt.

Gander, F., Proyer, R. T., Ruch, W., \& Wyss, T. (in press). The good character at work: An initial study on the contribution of character strengths in identifying healthy and unhealthy work-related behavior and experience patterns. International Archives of Occupational and Environmental Health, doi: 10.1007/s00420-012-0736-x.

Gillham, J., Adams-Deutsch, Z., Werner, J., Reivich, K., Coulter-Heindl, V., Linkins, M., et al. (2011). Character strengths predict subjective well-being during adolescence. The Journal of Positive Psychology, 6, 31-44. doi:10.1080/17439760.2010.536773.

Harter, J. K., \& Blacksmith, N. (2010). Employee engagement and the psychology of joining, staying in, and leaving organizations. In A. P. Linley, S. Harrington, \& N. Garcea (Eds.), Oxford handbook of positive psychology and work (pp. 121-130). New York: Oxford University Press.

Holland, J. L. (1997). Making vocational choices (3rd ed.). Odessa, FL: Psychological Assessment Resources.

Lounsbury, J. W., Fisher, L. A., Levy, J. J., \& Welsh, D. P. (2009). An investigation of character strengths in relation to the academic success of college students. Individual Differences Research, 19, 411-418. doi:10.1016/j.lindif.2009.03.001.

Park, N., \& Peterson, C. (2006). Moral competence and character strengths among adolescents: The development and validation of the Values in Action Inventory of Strengths for Youth. Journal of Adolescence, 29, 891-909. doi:10.1016/j.adolescence.2006.04.011.

Peterson, C., Park, N., \& Seligman, M. E. P. (2005). Assessment of character strengths. In G. P. Koocher, J. C. Norcross, \& S. S. Hill III (Eds.), Psychologists' desk reference (2nd ed., pp. 93-98). New York: Oxford University Press.

Peterson, C., \& Seligman, M. E. P. (2004). Character strengths and virtues: A handbook and classification. Washington, DC: American Psychological Association.

Preacher, K. J., \& Hayes, A. F. (2004). SPSS and SAS procedures for estimating indirect effects in simple mediation models. Behavior Research Methods, Instruments, and Computers, 36, 717-731.

Proyer, R. T. (2006). The relationship between vocational interests and intelligence: Do findings generalize across different assessment methods? Psychology Science, 48, 463-476.

Proyer, R. T. (2007). Convergence of conventional and behavior-based measures: Towards a multimethod approach in the assessment of vocational interests. Psychology Science, 49, 168-183.

Proyer, R. T., \& Häusler, J. (2007a). Assessing behavior in standardized settings: The role of objective personality tests. International Journal of Clinical and Health Psychology, 7, 537-546.

Proyer, R. T., \& Häusler, J. (2007b). Gender differences in vocational interests and their stability in different assessment methods. Swiss Journal of Psychology, 66, 243-247. doi:10.1024/1421-0185.66.4.243.

Proyer, R. T., \& Häusler, J. (2008). Multimethodische Objektive Interessentestbatterie (MOI) [Multimethod Objective Interest Test-battery]. Mödling, Austria: Schuhfried.

Proyer, R. T., Ruch, W., \& Buschor, C. (in press). Testing strengths-based interventions: A preliminary study on the effectiveness of a program targeting curiosity, gratitude, hope, humor, and zest for enhancing life satisfaction. Journal of Happiness Studies, doi:10.1007/s10902-012-9331-9.

Ruch, W., Weber, M., Park, N., \& Peterson, C. (in press). Adaptation and validation of the German Values in Action Inventory of Strengths for Youth (German VIA-Youth). European Journal of Psychological Assessment.

Seligman, M. E. P., \& Csikszentmihalyi, M. (2000). Positive psychology: An introduction. American Psychologist, 55, 5-14. doi:10.1037//0003-066X.55.1.5.

Seligman, M. E. P., Steen, T., Park, N., \& Peterson, C. (2005). Positive psychology progress: Empirical validation of interventions. American Psychologist, 60, 410-421. doi:10.1037/0003-066X.60.5.410.

Snyder, C. R., Ritschel, L. A., Rand, K. L., \& Berg, C. J. (2006). Balancing psychological assessments: Including strengths and hope in clients. Journal of Clinical Psychology, 62, 33-46. doi: 10.1002/jclp.20198. 
Super, D. E., \& Roper, S. A. (1941). An objective technique for testing vocational interests. Journal of Applied Psychology, 25, 487-498. doi:10.1037/h0062004.

Weber, M., \& Ruch, W. (in press). The role of a good character in 12-year-old school children: Do character strengths matter in the classroom? Child Indicators Research, doi:10.1007/s12187011-9128-0. 